\title{
HUBUNGAN SANITASI LINGKUNGAN DENGAN KEJADIAN DIARE PADA BALITA DI RAWAT INAP RSUD PRINGSEWU LAMPUNG
}

\section{THE RELATIONSHIP OF THE ENVIRONMENTAL SANITATION WITH THE EVENT OF DIARRHEA IN CHILDREN IN THE INAP HOSPITAL PRINGSEWU LAMPUNG HOSPITAL}

\author{
Yusnita \\ Fakultas Kesehatan Universitas Muhammadiyah Pringsewu Lampung \\ Email: umiyusnita@gmail.com
}

\begin{abstract}
The Relationship Of The Environmental Sanitation With The Event Of Diarrhea In Children In The Inap Hospital Pringsewu Lampung Hospital. Diarrhea is a digestive system disease that can interfere with activities, diarrhea must be overcome immediately because it can cause fluid loss and death, especially in infants. Factors that can cause diarrhea include poor environmental sanitation such as the disposal of human waste that is not in accordance with health standards and the provision of clean water used for daily needs. The purpose of this study was to determine the relationship of environmental sanitation with the incidence of diarrhea in toddler patients in the inpatient ward of Pringsewu Regional Hospital in 2020. This study used an analytical survey method with a cross sectional approach and the sample used was mothers who had toddlers with diarrhea as many as 40 person. The results of this study indicate that there is a relationship between the use of clean water sources with the incidence of diarrhea in toddler patients treated in the Pringsewu Regional Hospital in2020, as indicated by the chi-square test results obtained p-value of 0.021 with an OR value of 6.125. There is a relationship between the disposal of human waste with the occurrence of diarrhea, indicated by a p-value of 0.008 with an OR value of 8.75. It is expected that Pringsewu Regional Hospital staff can provide health education about the causes of diarrhea, so as to reduce the incidence of diarrhea in infants.

Keywords: Sanitation, Environment, Diarrhea
\end{abstract}

\begin{abstract}
Abstrak Hubungan Sanitasi Lingkungan Dengan Kejadian Diare Pada Balita Di Rawat Inap Rsud Pringsewu Lampung. Diare merupakan suatu penyakit system pencernaan yang dapat menggagu aktifitas, diare harus segera di atasi karena dapat mengakibatkan kehilangan cairan dan kematian terutama pada balita. Faktor yang dapat menyebabkan diare diantaranya sanitasi lingkungan yang kurang baik seperti pembuangan kotor anmanusia yang tidak sesuai dengan standar kesehatan dan penyediaan air bersih yang digunakan untuk keperluan sehari-hari. Tujuan dalam penelitian ini untuk mengetahui hubungan sanitasi lingkungan dengan kejadian diare pada pasien balita di ruang rawat inap anak RSUD Pringsewu tahun 2020. Penelitian ini menggunakan metode survey analitik dengan pendekatan cross sectional dan sampel yang digunakan adalah ibu-ibu yang memiliki balita dengan diare sebanyak 40 orang. Hasil penelitian ini menunjukan bahwa ada hubungan antara penggunaan sumber air bersih dengan kejadian diare pada pasien balita yang di rawat di ruang rawat inap RSUD Pringsewu tahun2020, ditunjukan dengan hasil uji chi-square didapatkan nilaip-value 0,021 dengan nilai OR 6,125. Ada hubunga nantara pembuangan kotoran manusia dengan kejadian diare, ditunjukkan dengan nilaip-value 0,008 dengan nilai OR 8,75. Diharapkan bagi petugas RSUD Pringsewu untuk dapat memberikan pendidikan kesehatan tentang penyebab diare, sehingga dapat menurunkan angka kejadian diare pada balita.

Kata kunci: Sanitasi, Lingkungan, Diare
\end{abstract}




\section{PENDAHULUAN}

Diare adalah kondisi dimana terjadi frekuensi defekasi yang biasa (lebihdaritiga kali sehari), juga perubahandalamjumlah dan konsistensi fesescair (Diyono dan Mulyanti, 2013). Diaremerupakan salah satupenyakit yang seringterjadi pada anakusia bayi dan balita (anak dengan usia dibawah lima tahun. Angka Angka kejadian diare di Provinsi Lampung tahun 2017 sebanyak 223.819 kasus atau sekitar 63,8\% dari keseluruhan penyakit yang ada (Kemenkes, 2017). Diare pada balita merupakan penyakit serius apabila tidak di tangani secara baik akan menyebabkan dehidrasi dan menyebabkan kematian (Wijaya \& Putri, 2013). Faktor yang dapat menyebabkan diare diantaranya sanitasi lingkungan yang kurang baik seperti pembuangan kotoran manusia yang tidak sesuai dengan standar kesehatan dan penyediaan air bersih yang digunakan untuk keperluan seharihari (Notoatdmojo, 2012).

Penelitian ini bertujuan untuk mengetahui hubungan antara sanitasi lingkungan dengan kejadian diare. Tujuan dijabarkan menjadi dua yaitu: hubungan antara pembuangan kotoran manusia dengan kejadian diare dan hubungan antarasumber air bersih yang digunakan dengan kejadian diare. Penelitian ini dapat memberikan manfaat bagi institusi Pendidikan, tempat pelayanan Kesehatan untuksaling bahu membahu menurunkan angka kejadian diare. Definisi operasional dalam penelitian ini menjelaskan tiga variable yaitu pembuangan kotoran manusia, sumber air bersih, dan diare.

\section{METODE}

Jenis penelitian yang digunakan adalah survey analitik dengan pendekatan Cross sectional yaitu desain penelitian analitik yang bertujuan untuk mengetahui hubungan antara variable dimana variable independent dan variabeldependendiidentifikasi pada satuwaktu. Penelitian ini dilakukan di rumah sakit umum daerah Pringsewu pada bulan November 2019 sampai dengan Januari 2020. Populasi dari penelitian ini adalah balita yang terkena diare pada bulan Agustus sampai dengan Oktober 2019 di ruang rawat inap anak sejumlah 40 orang. Dan sampel merupakan ibu-ibu yang memiliki balita dengan diare yang berjumlah 40 orang menggunakan tehnik total sampling.
Tehnik pengumpulan data menggunakan data primer. Pengumpulan data menggunakan kuesioner (lembar ceklist) dengan total pertanyaan berjumalah 20 terdiri dari 3 pertanyaan tentang diare, 12 pertanyaan tentang pembuangan kotoran manusia dan 5 pertanyaan tentang sumber air bersih. Sebelumnyadilakukan uji validitas dan uji reabilitas.

Teknik Analisa data yaitu Analisa univariat yang di tampilkan dalam bentuk distribusi frekuensi dan Analisa bivariat dengan menggunakan uji chi-square. Analisa bivariat untuk mengetahui hubungan pembuangan kotoran manusia dengan kejadian diare dan mengetahui hubungan hubungan sumber air bersih dengan kejadian diare.

\section{HASIL}

Hasil Analisa univariat. Tabel 1 menunjukkan pembuangan kotoran manusia yang memenuhisyarat, memiliki frekuensi terbanyak yaitu 23 responden $(57,5 \%)$ dibandingakn dengan pembuangan kotoran manusia yang tidak memenuhi syarat sebesar 17 responden $(42,5 \%)$. Tabel 2 menunjukkan responden yang menggunakan sumber air bersihmemiliki frekuensi terbanyak yaitu 22 (55\%) dan responden yang tidak menggunakan sumber air bersih sebanyak 18 (45\%). Tabel 3 menjelaskan responden yang mengalami diare memiliki frekuensi terbanyak yaitu $22(55 \%)$ dan responden yang tidak mengalami diare berjumlah 18 (45\%).

Hasil Analisa bivariat. Tabel 4 menunjukkan responden yang menggunakan air bersih dan tidak mengalami diare sebanyak 14 responden $(63.6 \%)$ dan responden yang tidak menggunakan air bersih yang mengalami diaresebanyak 14 responden (77.8\%). Berdasarkan hasil uji statistik diketahui bahwa $p$ value yaitu $0,021<0,05$ ( $p$-value $<0,05$ ), sehingga Ho ditolak. Hal ini menunjukan bahwa terdapat hubungan antara penggunaan sumber air dengan kejadian diare. Hasil penelitianini juga menunjukan nilai OR sebesar 6.125 yang berarti balita yang menggunakan sumber air tidak bersih memiliki resiko 6.125 kali lebih besar dibandingkan dengan balita yang menggunakan sumber air bersih.

Tabel 5 memperlihatkanresponden yang memiliki pembuangan tinja memenuhi syarat dan tidak menderita diaresebanyak 8 responden 
(68.4\%) dan responden dengan pembuangan tinja yang tidak memenuhi syarat yang mengalami diare sebanyak 14 responden $(85.7 \%)$.Berdasarkan hasil uji statistik diketahui bahwa $p$-value yaitu $0,008<0,05$ ( $p$-value < $0,05)$, sehingga Ho ditolak. Hal ini menunjukan bahwa terdapat hubungan antara pembuangan kotoran manusia dengan kejadian diare. Hasil penelitianini juga menunjukan nilai OR sebesar 8.750 yang berarti balita yang tidak memenuhi syarat dalam pembuangan kotoran manusai memiliki resiko 8.750 kali lebih besar dibandingkan dengan balita yang memiliki pembuangan kotoran manusia memenuhi syarat.

Tabel 1. Distribusi Responden Berdasarkan Pembuangan Kotoran Manusia

\begin{tabular}{ccc}
\hline $\begin{array}{c}\text { PembuanganKoto } \\
\text { ran }\end{array}$ & Jumlah & Presentasi (\%) \\
\hline Memenuhisyarat & 23 & 57,5 \\
\hline $\begin{array}{c}\text { Tidakmemenuhis } \\
\text { yarat }\end{array}$ & 17 & 42,5 \\
\hline Total & 40 & 100 \\
\hline
\end{tabular}

Tabel 2. DistribusiRespondenBerdasarkanSum ber Air Bersih

\begin{tabular}{ccc}
\hline Sumber Air Bersih & Jumlah & Presentasi (\%) \\
\hline $\begin{array}{c}\text { Menggunakan air } \\
\text { bersih }\end{array}$ & 22 & 55 \\
\hline $\begin{array}{c}\text { Tidakmenggunakan } \\
\text { air bersih }\end{array}$ & 18 & 45 \\
\hline Total & 40 & 100 \\
\hline
\end{tabular}

Tabel 3. Distribusi Responden Berdasrkan Kejadian Diare

\begin{tabular}{ccc}
\hline Kejadiandiare & Jumlah & Presentasi $(\%)$ \\
\hline Tidakdiare & 18 & 45 \\
\hline Diare & 22 & 55 \\
\hline Total & 40 & 100 \\
\hline
\end{tabular}

Tabel 4. Hubungan antara Sumber Air Bersih dengan Kejadian Diare

\begin{tabular}{|c|c|c|c|c|c|c|c|c|}
\hline \multirow{3}{*}{ Sumber air } & \multicolumn{4}{|c|}{ Kejadiandiare } & \multirow{2}{*}{\multicolumn{2}{|c|}{ Total }} & \multirow{3}{*}{$\begin{array}{c}\mathrm{P} \\
\text { Val } \\
\text { ue } \\
\end{array}$} & \multirow{3}{*}{$\begin{array}{c}\mathrm{OR} \\
95 \% \\
\mathrm{CI}\end{array}$} \\
\hline & \multicolumn{2}{|c|}{ Tdk Diare } & \multicolumn{2}{|c|}{ Diare } & & & & \\
\hline & $\mathrm{N}$ & $\%$ & $\mathrm{~N}$ & $\%$ & $\mathrm{~N}$ & $\%$ & & \\
\hline $\begin{array}{c}\text { Menggunaka } \\
\mathrm{n} \text { air bersih }\end{array}$ & 14 & 63,6 & 8 & $\begin{array}{l}36, \\
4\end{array}$ & 22 & 100 & $\begin{array}{l}0,0 \\
21\end{array}$ & 6,125 \\
\hline $\begin{array}{c}\text { Tidakmengg } \\
\text { unakan air } \\
\text { bersih }\end{array}$ & 4 & 22,2 & 14 & $\begin{array}{l}77, \\
8\end{array}$ & 18 & 100 & & \\
\hline Total & 18 & 40 & 22 & 60 & 40 & 100 & & \\
\hline
\end{tabular}

Tabel 5 Hubungan antara Pembuangan Kotoran Manusiadengan Kejadian Diare

\begin{tabular}{|c|c|c|c|c|c|c|c|c|}
\hline \multirow{3}{*}{$\begin{array}{c}\text { Pembuangan kotoran } \\
\text { manusia }\end{array}$} & \multicolumn{4}{|c|}{ Kejadian diare } & \multirow{2}{*}{\multicolumn{2}{|c|}{ Total }} & \multirow{3}{*}{$\begin{array}{l}\mathrm{P} \\
\text { Val } \\
\text { ue }\end{array}$} & \multirow{3}{*}{$\begin{array}{l}\text { OR } \\
95 \\
\% \\
\text { CI }\end{array}$} \\
\hline & \multicolumn{2}{|c|}{ Tidak diare } & \multicolumn{2}{|c|}{ Diare } & & & & \\
\hline & $\mathrm{N}$ & $\%$ & $\mathrm{~N}$ & $\%$ & $\mathrm{~N}$ & $\%$ & & \\
\hline Memenuhi syarat & 15 & 65,2 & 8 & 34,8 & 23 & 100 & 0,0 & 8,75 \\
\hline Tidak memenuhi syarat & 3 & 17,6 & 14 & 82,4 & 17 & 100 & 08 & \\
\hline Total & 18 & 40 & 60 & 60 & 40 & 100 & & \\
\hline
\end{tabular}

\section{PEMBAHASAN}

a. Hubungan sumber air dengan kejadian diare pada balita.

Hasil dari penelitian diketahui responden dengan penggunaan sumber air bersih yang tidak menderita diaresebanyak 14 responden $(36,4 \%)$ dan responden dengan penggunaan sumber air tidak bersih yang tidak mengalami diare sebanyak 14 responden $(77,8 \%)$. Hasil penelitian ini menunjukan bahwa responden yang mengalami diare di karnakan sumber air yang kurnag bersih.

Berdasarkan hasil uji statistic Chi-square diketahui bahwa $p$-value yaitu $0,021<\alpha 0,05$ ( $p$ value < 0,05), sehingga Ho ditolak. Hal ini menunjukan dapat disimpulkan bahwa terdapat hubungan antara sumber air dengan kejadian diare di RSUD Prungsewu Tahun 2020. Hasil penelitian ini juga menunjukan nilai OR sebesar 6.125 yang berarti balita yang menggunakan sumber air tidak bersih memiliki resiko 6.125 kali lebih besar dibandingkan dengan balita yang menggunakan sumber air bersih.

Hasil penelitian tersebut didukung oleh penelitian yang di lakukan oleh Sriwahyuni \& Soedirman (2015) yang menunjukan terdapat hubungan antara penggunaan sumber air bersih dengan kejadian diare pada balita dengan Pvalue $=(<0,005)$. Hasil peneltian ini berlawanan dengan hasil penelitian yang dilakukan oleh MblosiYand (2010) yang meneliti hubungan antara penggunaan sumber air dengan kejadian diare tahun 2010, hasil penelitian ini menunjukan tidak terdapat hubungan antara penggunaan sumber air dengan kejadian diare dengan nilai P-value 0.07

Menurut pendapat Budiman (2012) penggunaan sumber air dapat menyebabkan berbagai macam masalah kesehatan terutama masalah sistem pencernaan. Berbagai syarat sumber air yang dapat digunakan dan mampu memenuhi syarat kesehatan seperti, bebas dari kontaminasi kuman, bibit penyakit, bebas dari 
subtansi kimia, tidak berasa, tidak berbau. Diare merupakan salah satu dari beberapa penyakit yang banyak disebabkan oleh kontaminasi bakteri e.coli yang banyak ditemukan pada air.

Pendapat peneliti tentang adanya hubungan antara penggunaan sumber air dengan kejadian diare pada balita. diare merupakan penyakit yang dapat disebabkan oleh berbagai faktor namun salah satu faktor yang paling sering ditemui pada balita adalah infeksi bakteri e.coli yang didapat melalui penggunaan sumber air yang tidak terlindungi. Salah satu pencegahan agar sumber air terlindungi adalah menjaga kesehatan seperti lingkungan, air di edapakan terlebih dahulu sebelum di gunakan kebutuhan rumah tangga, dan di masak hingga mendidih terlebih dahulu sebelum di konsumsi.

\section{b. Hubungan Pembuangan kotoran manusia dengan kejadian diare pada balita.}

Berdasarkan tabel 4.5 terlihat bahwa responden dengan pembuangan tinja yang memenuhi syarat tidak diare sebanyak 8 responden $(34,8 \%)$ dan respoden dengan pembuangan kotoran tidak memenuhi syarat yang mengalami diare sebanyak14 responden $(82,4 \%)$. Hasil penelitian ini di jelaskan menunjukan bahwa responden yang mengalami diare di karnakan pembuangan tinja yang tidak memenuhi syarat yaitu tinja mengotori permukaan tahah,dan air.

Berdasarkanhasil uji statistic Chi-square diketahui bahwa $p$-value yaitu $0,008<\alpha 0,05$ ( $p$ value < 0,05), sehingga Ho ditolak. Hal ini menunjukan dapat disimpulkan bahwa terdapat hubungan antara pembuangan kotoran manusia dengan kejadian diare di RSUD Prungsewu Tahun 2020. Hasil penelitianini juga menunjukannilai OR sebesar 8.750 yang berartibalita yang menggunakan sumber air tidak bersih memiliki resiko 8.750 kali lebuh besar dibandingkan dengan balita yang menggunakan sumber air bersih.

Hasil penelitian ini sejalan dengan penelitian yang dilakukan oleh $\mathrm{Zulfa}$ (2017) yang meneliti faktor-faktor yang mempengaruhi kejadian diare pada balita. Hasil penelitian menunjukan bahwa dari sampel yang diteliti menunjukan ada hubungan antara pembuangant injadengan kejadian diare dengan nilai $\mathrm{Pv}=0,045$.
Menuru pendapat Wijaya \& Putri (2013) diare merupakan salah satu penyakit yang sangat identik dengan factor lingkungan. Lingkungan yang tidak sehat dapat meningkatan resiko seseorang khususnya balita terserang diare. Masalah lingkungan penyebab diare yang sering ditemui adalah. pembuangan tinja, Tinja manusia merupakan hasil akhir dari proses pengolahan makanan dalam tubuh manusia yang menyebabkan pemisahan dan pembuangan zatzat yang tidak dibutuhkan oleh tubuh dan kuman penyakit. Pembuangan tinja yang tidak memenuhi syarat dapat mengakibatkan kontaminasi pada air, tanah, atau menjadi sumber infeksi, dan akan mendatangkan bahaya bagi kesehatan, karena penyakit yang tergolong waterborne disease akan mudah berjangkit. Bahaya kesehatan yang dapat ditimbulkan akibat pembuangan kotoran secara tidak baik adalah pencemaran tanah, pencemaran air, kontaminasi makanan, dan perkembangbiakan lalat, sehingga mempermudah masuknya bakteri kedalam system pencernaan manusia.

Menurut pendapat peneliti kejadian diare yang tinggi saat ini dapat disebabkan oleh pembuangan kotoran manusia atau tinja. Semakin dekat pembuangan tinja dengan sumber air yang digunakan dalam aktifitas sehari-hari, maka akan semakin tinggi pula resiko seseorang terkena diare.

\section{SIMPULAN}

Simpulan penelitian adalah: ada hubungan antara sumber air bersih dengan kejadian diare pada balita di Rumah Sakit Umum Daerah Pringsewu tahun 2020. Berdasarkan analisis data diperoleh nilai $p$-value $0.021<0,05$. Sehingga Ho ditolakdengannilai OR 6.125.Ada hubunganantara Pembuangan kotoran manusia dengan kejadian diare pada balita di Rumah Sakit Umum Daerah Pringsewu tahun 2020. Berdasarkan analisis data diperoleh nilaip-value $0.008<0,05$. Sehingga Ho ditolak, dengan nilai ORadalah8.750.

\section{SARAN}

Untuk mencegah kejadian diare kita semua harus dapat menjaga sanitasi lingkungan diantara pembuangan kotoran manusia yang memenuhi syarat Kesehatan, penggunakan sumber air bersih. Bagi peneliti selanjutnya bias 
meneliti tentang kejadian diare yang dihubungkan dengan factor maknan dan factor psikologis.

\section{DAFTAR PUSTAKA}

Budiman. (2012). Kesehatan Lingkungan. Jakrta: EGC.

Kemenkes RI. (2017). Buku Pedoman Pelaksanaan Program P2 DIARE. Jakarta: Ditjen PPM dan PL.

Mblosi, A. (2010). Hubungan Sanitasi lingkungan denganKejadian Diare pada Masyarakat Desa Kaofe Kecamatan Kadatua Kabupaten Buton. Dikutipdari

Notoatmodjo, S. (2012). Metodologi Penelitian Kesehatan. Jakarta: RinekaCipta.

Saputri. N dan Puji Astuti. Y (2011). Hubungan Faktor Lingkungan dengan Kejadian Diare pada Balita di Puksesmas Bernung. Jurnal Ilmu Keperawatan dan Kebidanan. Vol 10, No 1 (2019)

Nurwinda. S (2019) Terapkan Perilaku Hidup Bersih dan Sehat dengan Optimalkan Cuci Tangan dalam Upaya Pengendalian Infeksi.

Sriwahyuni, M, \& Soedirman, O. (2015). Hubungan Faktor Lingkungan dan perilaku ibu dengan penyakit diare pada balita di Surabaya. Jurnal Promkes, 2,11.

Wijaya,S., \& Putri. M. (2013). KMB I. Yogyakarta: Nuha Medika.

Zulfa, Yandra. (2017). Hubungan Sanitasi Lingkungan Dengan Kejadian Diare pada Balita.

Dikutidarihttp://scholar.unand.ac.id/2624 5\%. repositori.uinalauddin.ac.id/6507/1/Anwar\%20Mbolosi opt.pdf. 